\title{
RE-DESAIN HUTAN KOTA SEBAGAI IDENTITAS KAWASAN
}

\author{
Debby Budi Susanti \\ Dosen Prodi Arsitektur, Fak. Teknik Sipil dan Perencanaan, ITN Malang \\ e-mail: budisusantidebby@gmail.com \\ Tri Poespowati \\ Dosen Prodi Teknik Kimia, Fak. Teknologi Industri, ITN Malang \\ e-mail: poespowati@yahoo.com.au \\ Soeranto Darsopuspito \\ Dosen Prodi Arsitektur, Fak. Teknik Sipil dan Perencanaan, ITN Malang \\ e-mail: soeranto@ftsp.itn.ac.id
}

\begin{abstract}
ABSTRAK
Ketersediaan Ruang Terbuka Hijau khususnya pada wilayah perkotaan sangat penting mengingat besarnya manfaat yang diperoleh dari keberadaan RTH tersebut. Kawasan Ruang Terbuka Hijau ini juga merupakan tempat berolahraga, interaksi sosial bagi masyarakat yang dapat mengurangi tingkat stress akibat beban kerja dan menjadi tempat rekreasi keluarga bagi masyarakat perkotaan.

Adanya penelitian berbasis desain ini dilakukan bertujuan untuk mengubah tampilan dari Ruang Terbuka Hijau yang berlokasi di Hutan Malabar di Kelurahan Oro-oro Dowo, Kecamatan Klojen Malang. Pertimbangan penelitian rancangan ini dilakukan berdasarkan ide atau gagasan dari seluruh masyarakat Kelurahan Oro-oro Dowo yang dikumpulkan pada masing-masing RW. Metode pengumpulan gagasan ini dilakukan dengan mengakomodir usulan ide dari seluruh masyarakat, kemudian menyaringnya dengan mengambil gagasan yang terbaik melalui proses musyawarah. Setelah terpilihnya gagasan yang terbaik maka tahap selanjutnya dilakukan penetapan usulan desain.
\end{abstract}

Kata kunci : ruang terbuka hijau, hutan kota, anggrek

\begin{abstract}
Availability of Green Open Space especially in urban areas is very important considering the amount of benefits gained from the presence of green space. Green Open Space Area is also a place of sports, social interaction for people who can reduce stress levels due to workload and become a family recreation for urban communities.

The existence of this design-based research is aimed to change the appearance of Green Open Space located in Malabar Forest in Orooro Dowo Village, Klojen Malang Sub-district. The consideration of
\end{abstract}

PAWON: Jurnal Arsitektur, Volume II Nomor 02, Juli-Desember Tahun 2018, ISSN 2597-7636 
this design study is based on ideas or ideas from the entire community of Oro-oro Dowo Villages that are collected in each RW. This idea-gathering method is done by accommodating the ideas of the whole community, then filtering it out by taking the best idea through the deliberation process. After the election of the best idea then the next stage made the design proposal.

\section{Keywords : open space, urban forest, orchid}

\section{PENDAHULUAN}

Kota Malang adalah sebuah kota yang terletak di Provinsi Jawa Timur, Indonesia. Kota ini terletak $90 \mathrm{~km}$ sebelah selatan Surabaya dan merupakan kota terbesar di kedua di Jawa Timur setelah Surabaya, serta merupakan salah satu kota terbesar di Indonesia menurut jumlah penduduk. Selain itu, Malang juga merupakan kota terbesar kedua di wilayah Pulau Jawa bagian selatan setelah Bandung. Kota Malang berada di dataran tinggi yang cukup sejuk, dan seluruh wilayahnya berbatasan dengan Kabupaten Malang. Luas wilayah kota Malang adalah 252,10 km2. Bersama dengan Kota Batu dan Kabupaten Malang, Kota Malang merupakan bagian dari kesatuan wilayah yang dikenal dengan Malang Raya (Wilayah Metropolitan Malang). Wilayah Malang Raya yang berpenduduk sekitar 4 juta jiwa adalah kawasan metropolitan terbesar kedua di Jawa Timur setelah Gerbang Kertosusila. Kawasan Malang Raya dikenal sebagai salah satu daerah tujuan wisata utama di Indonesia dan Jawa Timur khususnya.Jurnal Pawon dicetak tidak berwarna, untuk itu gambar, foto, grafik, tabel resulosinya supaya disesuaikan. Bila dicetak tidak jelas bukan bukan tanggung jabab penerbit.

Aparatur pemerintahan yang langsung bersentuhan dengan potensi di setiap kawasan adalah kelurahan. Kelurahan merupakan dasar dari satuan pemerintahan yang terkecil dari suatu komunitas pemerintahan negara. Sehingga boleh dikatakan bahwa keberhasilan dalam melakukan pembangunan juga tergantung dari sejauh mana partisipasi masyarakat setempat beserta aparatur pemerintahan dalam perencanaan pembangunan tersebut. Dalam arti masyarakat harus ikut berpartisipasi dan diberi kepercayaan dan kewenangan yang cukup dalam mengurusi rumah tangga kelurahannya, sehingga bisa mandiri dan sesuai dengan potensi dan sumber daya yang dimiliki daerah tersebut.

Kelurahan Oro-oro Dowo ini adalah salah satu kelurahan yang ada di kecamatan Klojen yang memiliki beberapa lahan terbuka (public space) yang cukup banyak dan luas, salah satunya adalah Hutan Kota Malabar. Hutan Kota Malabar atau yang dulunya bernama Lapangan Malabar memiliki luasan yang cukup luas, dahulu tempat ini dijadikan tempat berolah raga bagi masyarakat sekitar serta sekolah-sekolah yang dekat dengan

PAWON: Jurnal Arsitektur, Volume II Nomor 02, Juli-Desember 2018, ISSN 2597-7636 
tempat ini. Lapangan Malabar juga digunakan sebagai areal bermain bagi anak-anak sekitar. Seiring berjalannya waktu lapangan Malabar ini beralih fungsi menjadi hutan kota yang ditanami berbagai macam pepohonan tetapi sangat disayangkan pepohonan yang ditanam tidak ditata dengan rapi sehingga terkesan gelap. Karena gelapnya di Hutan Malabar sering dimanfaatkan oleh orang-orang yang tidak bertanggungjawab untuk melakukan tindakan-tindakan yang melanggar norma dan hukum yang ada.

Melihat keadaan tersebut akhirnya pemerintah kota Malang mengambil inisiatif untuk mengubah tampilan Hutan Malabar Menjadi hutan yang lebih tertata dan lebih indah. Pemerintah Kota Malang menggandeng sponsor untuk merombak tampilan Hutan Malabar. Dan akhirnya Hutan Malabar menjadi lebih rapi, tertata, dan indah. Melihat sudah tertatanya Hutan Malabar menggugah warga Kelurahan Oro-oro Dowo untuk lebih memperindah dan menonjolkan unsur edukasi serta memiliki nilai jual di masyarakat umum dan mampu menumbuhkan lapangan kerja baru untuk masyarakat di sekitar kawasan tersebut. Salah satu cara yang digagas oleh masyarakat Kelurahan Oro-oro Dowo adalah dengan menempatkan anggrek di tiap-tiap pohon yang ada di Hutan Malabar serta membuat tempat untuk pembenihan anggrek sehingga masyarakat selain dapat menikmati indahnya anggrek dan sejuknya udara di bawah pepohonan Hutan Malabar juga dapat melihat cara mengembangbiakkan anggrek. Pemilihan pohon anggrek sebagai tanaman unggulan di kawasan tersebut karena habitat asli tanaman anggrek adalah menempel pada batang pohon dan iklim di wilayah Kota Malang sangat cocok untuk perkembangbiakan tanaman tersebut.

\section{TINJAUAN PUSTAKA}

\subsection{Sejarah Perkembangan Kawasan}

Hutan kota Malabar terletak di wilayah Kelurahan Oro-oro Dowo Kecamatan Klojen dengan luas $16.178 \mathrm{~m}^{2}$. Pada awal zaman pemerintahan Belanda, hutan Malabar ini merupakan lahan kosong yang dimanfaatkan sebagai resapan air dan tempat bermain anak-anak dari kampong sekitar, didaamnya terdapat bangunan kolam atau yang biasa disebut "Bozem" yang berfungsi sebagai tampungan air dari lokasi sekitar.

Pada tahun 2013 Pemerintah Kota Malang mengukuhkan lokasi ini sebagai HUTAN KOTA MALABAR, sesuai nama lokasinya yaitu di Jalan Malabar, dengan Surat Keputusan Walikota Malang No. 220/2013, tahun demi tahun penghijauan terus diupayakan dengan tujuan menambah rindang Ruang Terbuka Hijau, fungsi konservasi air, resapan air dan paruparu kota, sebagai penyeimbang lingkungan Perkotaan, sekaligus sebagai tempat rekreasi yang menyegarkan.

PAWON: Jurnal Arsitektur, Volume II Nomor 02, Juli-Desember Tahun 2018, ISSN 2597-7636 


\subsection{Gambaran Penduduk}

Kelurahan Oro-oro Dowo merupakan kelurahan yang terletak di wilayah Kecamatan Klojen, Kota Malang. Kelurahan ini terdiri dari 10 RW (Rukun Warga) dan 97 RT (Rukun Tetangga). Kelurahan ini memiliki luas wilayah $1.375 \mathrm{~km} 2$. Berdasarkan data resminya, Kelurahan Oro-oro Dowo dihuni oleh 13.616 jiwa penduduk yang terdiri dari 6.627 jiwa pria dan 6.989 jiwa wanita.

Dengan adanya kondisi sekitar Hutan Malabar yang dikelilingi pasar tradisional Oro-oro Dowo, masyarakat sekitar berpotensi memiliki lapangan pekerjaan didaerah tersebut. Dan masyarakat sekitar sangat peduli terhadap maju dan berkembangnya terhadap fasilitas umum yang ada di lingkungan mereka.

\subsection{Gambaran Fisik/Rona Alam}

Di Kelurahan Oro-oro Dowo terdapat Jalan Besar ljen Boulevard yang membentang dari selatan ke utara. Potensi wisata sejarah sangat besar di jalan ini, lantaran terdapat Museum Brawijaya, Monumen Melati, Monumen dan Taman Makam Pahlawan TRIP, serta bangunan rumah dengan arsitektur khas Belanda di zaman kolonial. Hutan Malabar terletak di timur Jalan Besar ljen. Hutan Kota Malabar ini dikelilingi oleh pasar tradisional Oro-oro Dowo, rumah warga tebaik tingkat nasional serta dikelilingi jalan besar sehingga mudah diakses. Di tengah Hutan Kota Malabar terdapat kolam air yang konon menjadi sumber untuk mengairi taman-taman di kota Malang. Hutan kota ini begitu banyak manfaatnya. Memasuki bagian dalam hutan ini, memiliki hawa yang sejuk dan terdengar kicauan burung. Hutan Kota Malabar ini memiliki pohon yang lebat, sehingga berada di dekatnya pun akan terasa hawa yang segar. Banyak sekali keberagaman flora serta fauna yang ada di dalamnya, untuk faunanya sendiri kebanyakan dari jenis serangga seperti semut, angang-angang, laba-laba, bekicot, kupu-kupu dll. Sedangkan untuk floranya kebanyakan adalah tanaman tahunan.

\section{METODE PENELITIAN}

\subsection{Gambaran Fisik/Rona Alam}

Hutan Kota Malabar ini terletak di Kota Malang Jawa Timur, yang lebih spesifik lagi di Kecamatan Klojen, Kelurahan Oro-oro Dowo. Secara administratif, Kelurahan Oro-oro Dowo dikelilingi oleh kelurahan lainnya yang ada di Kota Malang. Di sebelah utara, Kelurahan Oro-oro Dowo berbatasan langsung dengan Kelurahan Samaan, Kecamatan Klojen. Sedangkan di sebelah timur, kelurahan 
ini berbatasan langsung dengan Kelurahan Klojen, Kecamatan Klojen. Sementara di sebelah selatan, Kelurahan Oro-oro Dowo berbatasan dengan Kelurahan Kauman, Kecamatan Klojen. Lalu, di sebelah barat, kelurahan ini berbatasan dengan Kelurahan Gading Kasri, Kecamatan Klojen
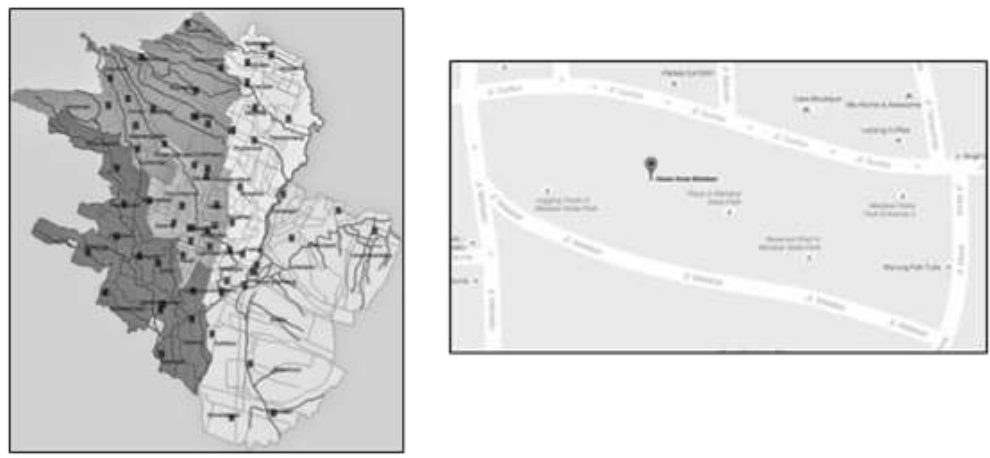

Gambar 1. Gambar Peta Kota Malang dan Peta Hutan Malabar

\subsection{Gambaran Obyek}

Obyek yang diangkat dalam penelitian berbasis desain ini adalah Ruang Terbuka Hijau yang terletak di Jalan Malabar Kelurahan Oro-oro Dowo, Kecamatan Klojen, Kota Malang, Jawa Timur atau biasa disebut dengan Hutan Kota Malabar. Menurut gagasan yang telah dikumpulkan dari seluruh masyarakat kelurahan Oro-oro Dowo yang dikumpulkan pada masing-masing RW, Hutan Malabar ini akan dibenahi dengan cara menempatkan anggrek di tiap-tiap pohon yang ada di Hutan Malabar. Selain itu, dalam hutan Malabar ini akan dibuatkan tempat untuk pembenihan tanaman anggrek sehingga masyarakat dapat melihat cara mengembangbiakkan tanaman anggrek.

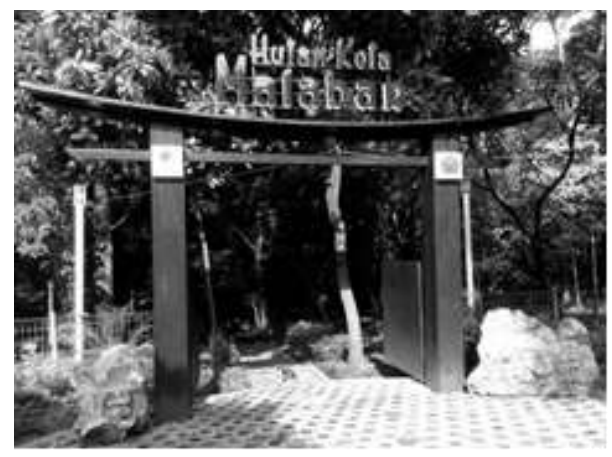

Gambar 2. Pintu Nasuk Hutan Nialaba

PAWON: Jurnal Arsitektur, Volume II Nomor 02, Juli-Desember Tahun 2018, ISSN 2597-7636 
Dengan adanya perubahan Hutan Malabar menjadi lebih rapi, tertata, dan indah, membuat seluruh pihak yang berwenang dan warga Kelurahan Oro-oro Dowo turut serta berpartisipasi dalam memperindah dan menonjolkan unsur edukasi serta memiliki nilai jual di masyarakat umum.

\subsection{Metode Pengumpulan Data}

Data dibedakan menjadi 2 (dua), yaitu : data primer dan data sekunder. Data primer adalah data yang diperoleh langsung di lapangan, sedangkan data sekunder adalah data yang melengkapi data primer, yaitu yang diperoleh dari instansi terkait berupa buku/dokumen/catatan yang diteliti atau suatu hasil penelitian. Untuk mendapatkan data yang tepat dan dapat mendukung proses analisis, maka ada beberapa hal yang perlu diperhatikan dalam pengambilan data, yaitu : menentukan faktor pengaruh, menentukan jenis data apa yang dibutuhkan, menentukan sumber-sumber data yang relevan, menentukan cara mendapatkan data dan alat yang digunakan untuk mendapatkan data tersebut.
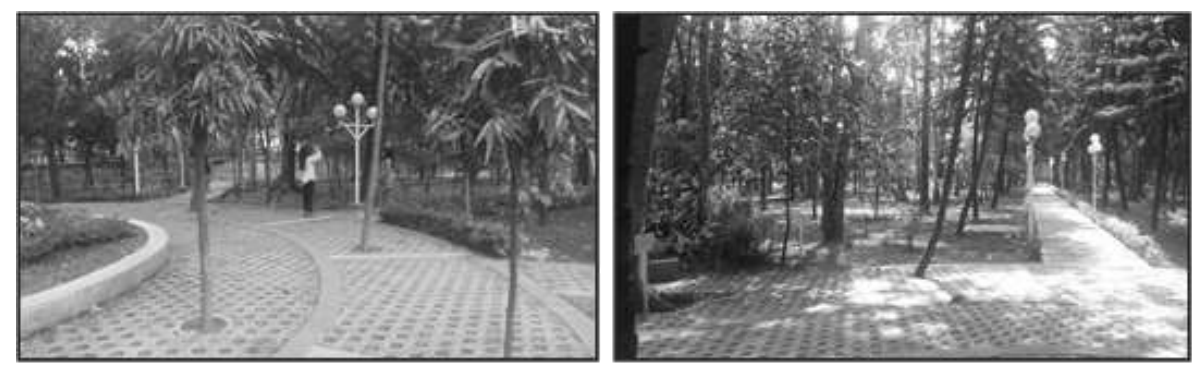

Gambar 3. Foto Kondisi Di dalam Hutan Malabar Sumber : Dokumen Pribadi

\section{HASIL DAN PEMBAHASAN}

\subsection{Analisa}

Hasil analisa dari beberapa bangunan yang sudah ada di dalam lokasi Hutan malabar antara lain :

- Rumah Kompos

Rumah kompos ini kurang terawat dan letaknya yang sangat terbuka dari arah luar lokasi membuat hutan Malabar ini terkesan tidak indah dan kumuh atau kurang terawat.

PAWON: Jurnal Arsitektur, Volume II Nomor 02, Juli-Desember 2018, ISSN 2597-7636 


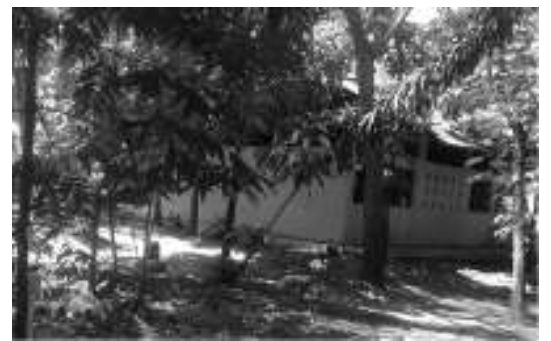

Gambar 4. Foto rumah kompos di Hutan Malabar

- Kolam Resapan

Keadaan kolam resapan yang kurang terawat dan kondisi kolam yang memiliki kemiringan dan kedalaman yang cukup tinggi sehingga memiliki dampak berbahaya terhadap keselamatan anak-anak maupun orang dewasa walaupun terdapat pembatas.

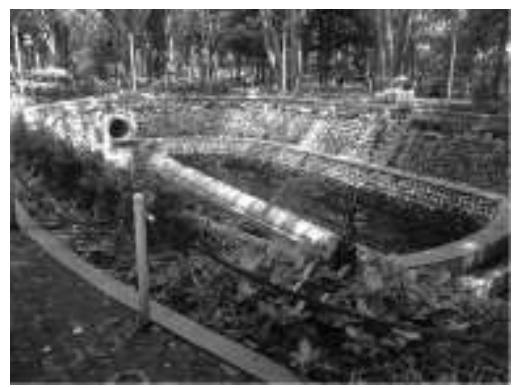

Gambar 5. Kondisi Kolam Resapan Yang Ada Di Hutan Malabar

- $\quad$ Pusat (Point of Interest)

Dalam lokasi Hutan Malabar ini terdapat Pusat bekumpul (Point Interset) didalamnya. Keadaanya hanya terdapat perkerasan berupa paving dan sedikit gundukan / kontur yang ada di salah satu sisi pinggiran perkerasan. Gundukan atau kontur ini dapat berpotensi sebagai point interest yang dimaksud dengan mendesain ulang tataannya dan merawatnya.
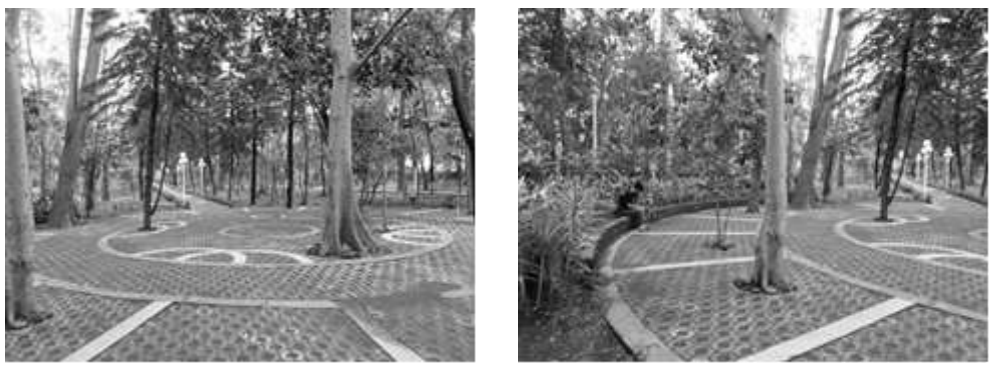

Gambar 6. Kondisi Pusat Kegiatan di Hutan Malabar

PAWON: Jurnal Arsitektur, Volume II Nomor 02, Juli-Desember Tahun 2018, ISSN 2597-7636 


\section{- Selasar}

Selasar yang ada teralu monoton dan penampilan pavingnya yang bolong-bolong mengurungkan niat pengunjung untuk mengitari seluruh Hutan Malabar, karena tidak nyamannya berjalan di atas paving tersebut dan kesan warna yang cenderung kesan muram.
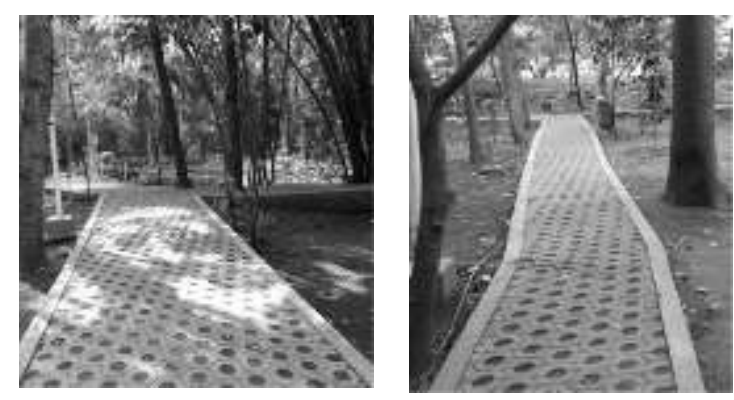

Gambar 7. Kondisi Selasar Di Hutan Malabar

\section{- $\quad$ Tempat Pembuangan Sampah Sementara (TPS)}

Hutan Malabar ini memiliki fasilitas tepat pembuangan sampah (TPS) yang terletak di pojokan yaitu di sisi timur hutan. Letak TPS yang ada pada hutan Malabar dipojok yang tampaknya dapat dikonsumsi oleh luar maupun dalam hutan. Kondisi TPS ini tanpa adanya penghalang yang menutupi zona servis dari TPS, sehingga mengganggu pemandangan dari sekitar TPS maupun mengganggu kenyamanan dan penghawaan pengunjung.

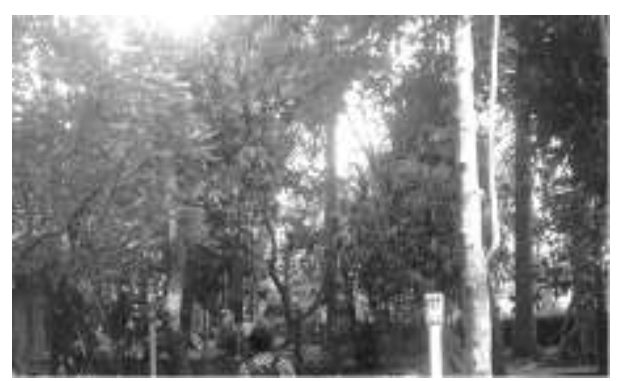

Gambar 8. Kondisi TPS di Hutan Malabar

- $\quad$ Lahan Kosong (Lahan Tanpa Perkerasan) 
Hutan Malabar memiliki banyak lahan kosong yang tidak dijadikan perkerasan yang sangat berpotensi untuk kawasan hijau. Dengan kosongnya ini memberikan kesan los yang dapat mengkonsumsi oksigen sepuasnya. Lahan kosong yang kurang terawat ini sangat sedikit memiliki penghijauan seperti rumput-rumputan. Sehingga menimbulkan kesan gelap terhadap hutan.
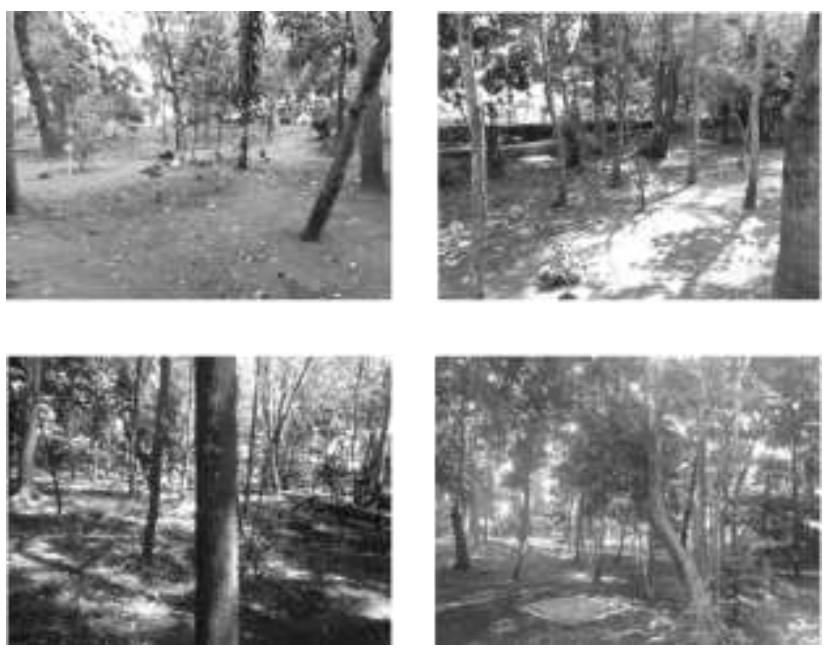

Gambar 9. Kondisi Lahan Kosong Di Hutan Malabar

Bagian ini berisi hasil analisis dan interpretasi atau diskusi hasil analisis. Uraikan secara terstruktur, rinci, lengkap dan padat, sehingga pembaca dapat mengikuti alur analisis dan pemikiran peneliti.

Posisi tabel sama dengan posisi foto atau grafik, yaitu ceter text, garis kolom untuk tabel ditiadakan, contohnya dapat dilihat pada tabel 1

\subsection{Konsep Umum Rancangan}

Cara merubah tampilan hutan Malabar adalah dengan menambahkan tanaman anggrek di tiap-tiap pohon yang ada di hutan Malabar. Selain menempelkan tanaman anggrek di pohon akan dibangun juga tempat pengembangbiakkan tanaman anggrek.

Dengan keadaan hutan Malabar yang semakin menarik membuat hutan ini dapat dijadikan tempat rekreasi, edukasi, serta mendatangkan

PAWON: Jurnal Arsitektur, Volume II Nomor 02, Juli-Desember Tahun 2018, ISSN 2597-7636 
pendapatan. Keuntungan yang dirasakan nantinya bukan hanya dinikmati oleh kelompok tertentu menalinkan dapat dinikmati masyarakat umum dan masyarakat Kelurahan Oro-oro Dowo khususnya. Tampilan hutan yang penuh dengan warna-warna yang dihasilkan dari tanaman anggrek yang sedang mekar bunganya membuat hutan Malabar tidak hanya berwarna gelap melainkan cerah dan sedap dipandang mata. Pengunjung hutan nantinya selain dapat menikmati indahnya bunga anggrek yang mekar, mereka juga dapat melihat pekembangbiakan tanaman anggrek. Dan tersedia juga bagi pengunjung yang berminat untuk membeli.

Pada rancangan Hutan Malabar ini dirancang dengan menonjolkan fisik atau menambah nilai jual hutan ini terhadap masyarakat dengan menarik. Perancangan ruang terbuka ini memanfaatkan kondisi eksisting tapak yang ada tanpa menambahkan perkerasan atau bangunan yang permanen. Maka dari itu berikut uraian konsep yang akan dirancang:

\section{Vertikal Garden}

Dibuatnya penempatan dan desain penataan vertikal garden disekitar rumah kompos dan toilet. Selain itu juga penempatan vertikal garden dibuat di sekitar TPS yang membutuhkan privasi dari fungsi servis. Penataan letak dan desain vertikal garden dibuat seindah mungkin agar membangun estetika hutan Malabar. Material yang dirancang untuk vertikal garden ini menggunakan kayu berukuran $5 \times 10 \mathrm{~cm}$ sebagai framenya dan bagian tengahnya diberi kawat yang dikaitkan ke frame kayu, lalu tanaman bias diletakkan atau dikaitkan di kawat.
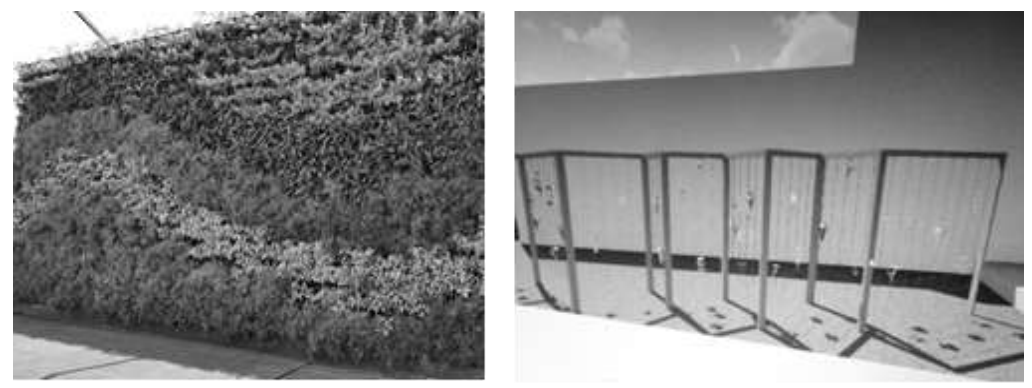

Gambar 10. Konsep Vertical Garden Pada Hutan Malabar

\section{Kolam Resapan}

Kolam resapan ditanami tanaman pagar / pembatas yaitu tanaman bayam merah yang ditanam di sekeliling / pinggir kolam bagian atas. Ketinggian dari tanaman bayam merah tersebut dibuat sekitar \pm 1 meter yang disesuaikan menurut desain yang telah dibuat tertera pada gambar rancangan. Lalu sisi terluar bayam merah akan diberi tanaman anggrek yang ditanam ditanah dan ditata sedemikian rupa.

PAWON: Jurnal Arsitektur, Volume II Nomor 02, Juli-Desember 2018, ISSN 2597-7636 

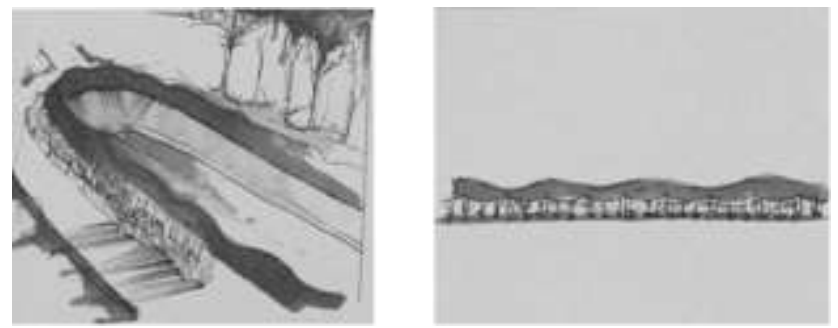

Gambar 11. Konsep Desain Sumur Resapan Hutan Malabar

\section{Pusat Berkumpul (Point Interest)}

Adanya gundukan / kontur disebagian pinggiran point interest tersebut akan didesain dengan menanami tanaman dan bunga-bunga yang diitata dengan pola yang tertata rapi dan di sebagian sisi gundukan / kontur ditanami bunga berwarna cerah yang diukir berhuruf atau menuliskan kata "HUTAN MALABAR"
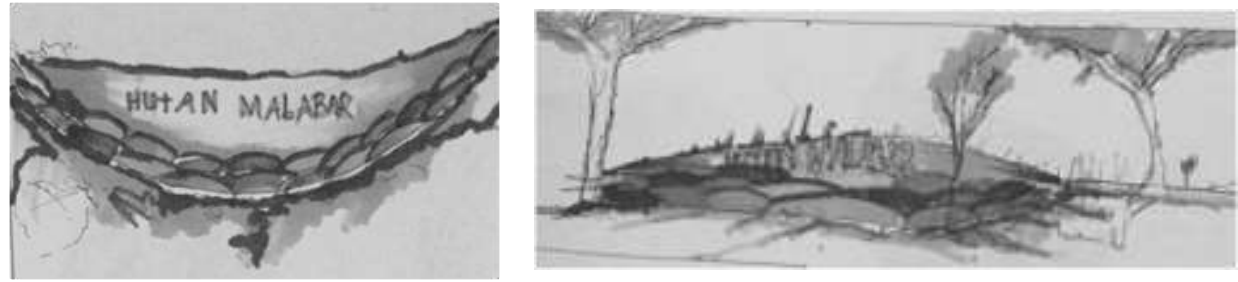

Gambar 12. Desain Pusat Berkumpul di Hutan Malabar

\section{Selasar}

Selasar akan dibuat dengan desain yang unik. Selasar didesain untuk berperan sebagai penunjuk arah ke point interest hutan Malabar. Selasar dengan desain unik ini dibuat di 3 selasar dengan desain yang berbedabeda. Desain Selasar 1 akan diletakan di selasar yang merupakan akses dari arah toilet menuju kolam resapan. Desain Selasar 2 akan dibuat di selasar yang merupakan akses dari arah kolam resapan menuju Pusat (point interest). Dan desain Selasar 3 akan dibuat di selasar yang merupakan akses dari pintu masuk 1 menuju Pusat (point interest). Penggunaan material dari desain selasar ini menggunakan kayu yang berukuran $5 \times 10 \mathrm{~cm}$ dengan finishing cat kayu.

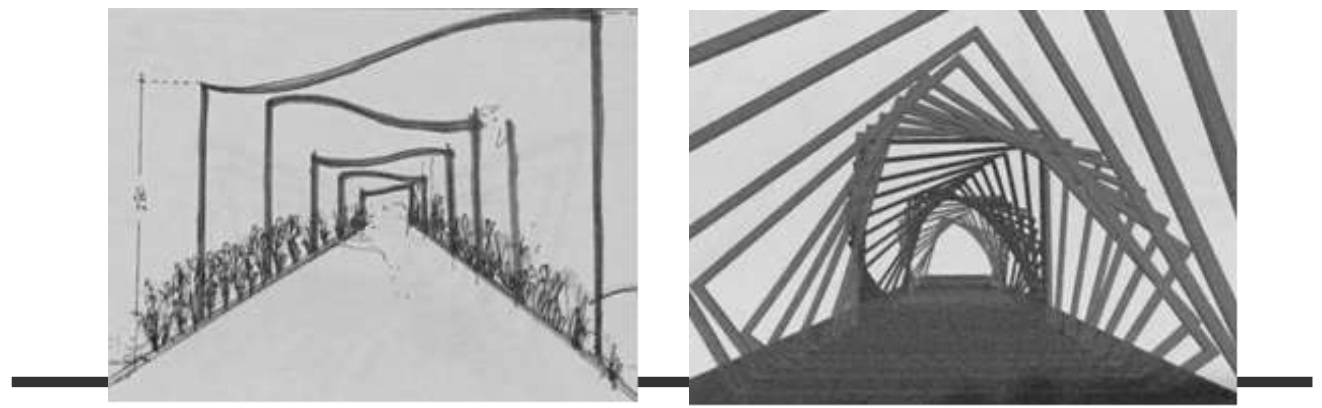

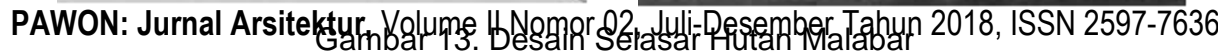




\section{Lahan Kosong Tanpa Perkerasan}

Kawasan yang kosong tidak terdapat perkerasan atau vegetasi yang menutupi banyak lahan akan dibuat tataan tanaman bunga beranekaragam warna yang memiliki pola lingkaran dengan bunga yang ditata sedemikian rapih.
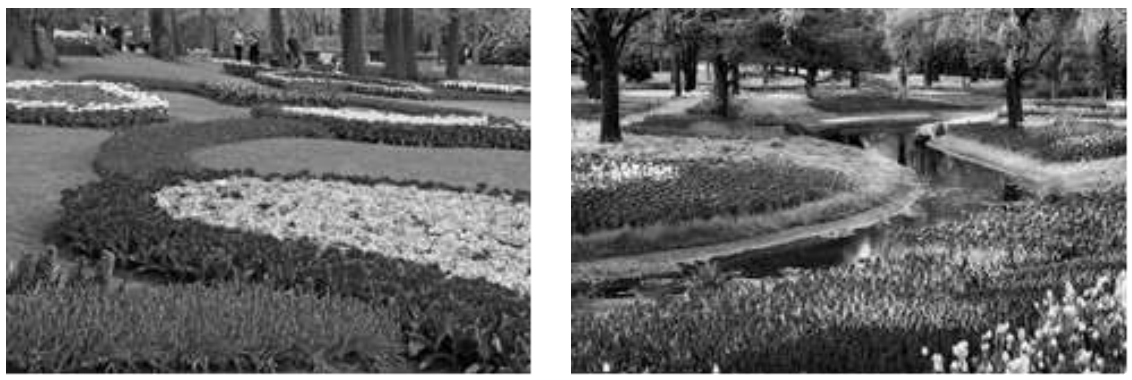

Gambar 14. Desain Lahan Tanpa Perkerasan Di Hutan Malabar

\section{KESIMPULAN}

Dalam merubah tampilan atau wajah hutan kota suatu kawasan perlu kerjasama dan partisipasi dari beberapa unsur masyarakat, yaitu ide/gagasan dari masyarakat, dukungan kebijakan dan dana dari pemerintah daerah, serta sumbangan saran dan ide dari akademisi untuk mewujudkan ide/gagasan tersebut. Masyarakat merupakan unsur utama dan terpenting pada perancangan sebuah kawasan. Rasa turut memiliki perlu ditanamkan pada masyarakat agar masyarakat turut menjaga dan merawat obyek rancangan.

Pemilihan unsur tanaman yang akan dijadikan fokus utama dalam sebuah rancangan hutan kota harus disesuaikan dengan kondisi iklim setempat dan memiliki karakteristik kekhasan pada suatu kawasan. Sehingga tidak hanya sebagai obyek wisata dan pengendali banjir kota, kawasan hutan kota juga diharapkan mampu menjadi kawasan edukasi bagi dunia pendidikan.

\section{DAFTAR PUSTAKA}

Hakim, Rustam. 1993. Unsur Perancangan Dalam Arsitektur Lansekap. Bandung.

Gunadi, Sugeng. 1989. Pedoman Perancangan Tapak Dan Lingkungan. Surabaya.

Linch, Kevin. 1971. Site Planning. Cambridge.

Frick, Heinz. 1996. Arsitektur dan Lingkungan. Yogyakarta. Kanisius.

Ashihara, Yoshinobu. Perancangan Arsitektur Dalam Arsitektur. Bandung. 